\title{
Effect of tree logging on reproductive performance in Blue Tits (Cyanistes caeruleus)
}

\author{
Seyed Mehdi Amininasab ${ }^{1,2} \cdot$ Charles C. Y. Xu ${ }^{1,3} \cdot$ Sjouke A. Kingma ${ }^{1} \cdot$ \\ Jan Komdeur ${ }^{1}$
}

Received: 11 January 2016/Revised: 11 August 2016/Accepted: 12 September 2016/Published online: 22 September 2016

(C) The Author(s) 2016. This article is published with open access at Springerlink.com

\begin{abstract}
For birds, habitat quality is largely determined by local vegetation, and reproductive performance can therefore be negatively influenced by anthropogenic activities. A tree logging event enabled us to examine the effect of removing trees of different maturities and types on the reproductive performance of Blue Tits (Cyanistes caeruleus). Against expectations, only the logging of small coniferous trees, but not larger and deciduous trees, was associated with a reduction in the number of eggs laid, whereas logging had no significant effect on lay date. Therefore, we conclude that modest logging activity has no or limited negative influence on Blue Tit reproductive performance.
\end{abstract}

Keywords Anthropogenic $\cdot$ Breeding $\cdot$ Clutch size · Habitat · Laying date $\cdot$ Logging

Communicated by F. Bairlein.

Electronic supplementary material The online version of this article (doi:10.1007/s10336-016-1393-8) contains supplementary material, which is available to authorized users.

Seyed Mehdi Amininasab

s.m.amini.nasab@rug.nl; smamininasab@yahoo.com

1 Behavioural and Physiological Ecology, Groningen Institute for Evolutionary Life Sciences, University of Groningen, P.O. Box 11103, 9700 CC Groningen, The Netherlands

2 Department of Environmental Science, Behbahan Khatam Alanbia University of Technology, Behbahan, Iran

3 Department of Ecology and Genetics, Evolutionary Biology Centre, Uppsala University, Uppsala, Sweden

\section{Zusammenfassung}

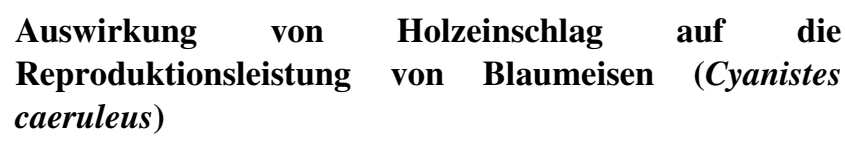

Habitatqualität wird für Vögel weitgehend bestimmt durch lokale Vegetation, wodurch die Reproduktionsleistung von Vögeln durch menschliche Aktivitäten negativ beeinflusst werden kann. Wir prüften die Auswirkungen von Holzeinschlag von Bäumen verschiedener Reife und Art auf die Reproduktionsleistung von Blaumeisen (Cyanistes caeruleus). Entgegen den Erwartungen hatte nur die Entfernung von kleinen Nadelbäumen einen reduzierenden Effekt auf die Anzahl der gelegten Eier, im Gegensatz zu Laub- und größeren Nadelbäumen. Der Holzeinschlag hatte auch keinen signifikanten Einfluss auf das Legedatum. Daraus schließen wir, dass moderater Holzeinschlag keinen oder nur begrenzten negativen Einfluss auf die Reproduktionsleistung der Blaumeise hat.

\section{Introduction}

Anthropogenic disturbances such as logging result in habitat loss and fragmentation, and can therefore affect avian biodiversity (Burivalova et al. 2015). For birds, food availability, and thus breeding habitat quality, is largely determined by local forest structure (Lambrechts et al. 2004; Mägi et al. 2009). While several studies have examined the effects of logging on reproduction in birds (Bourque and Villard 2001; Gram et al. 2003), few have used fine-scale indices on the level of individual trees. By relating changes in bird reproduction to the logging of 
specific trees of known maturities and types, it is possible to identify the proximate ecological factors that influence avian reproductive performance, which may help to inform forest management.

In winter 2013, trees were logged in a field site inhabited by Blue Tits (Cyanistes caeruleus) subject to long-term study. This created an ideal opportunity to investigate the effects of anthropogenic change in forest structure on reproductive parameters (laying date and number of eggs laid). We hypothesized that logging influences reproductive performance and that this effect is stronger for larger trees and for deciduous rather than coniferous trees, given their greater importance in providing food resources for Blue Tits (Amininasab et al. 2016).

\section{Materials and methods}

\section{Study population and data collection}

We studied a population of Blue Tits inhabiting 188 nestboxes (around $2 \mathrm{~m}$ high) in mixed deciduous and coniferous forest in 'De Vosbergen' in the Netherlands $\left(53^{\circ} 08^{\prime} \mathrm{N}\right.$, $06^{\circ} 35^{\prime} \mathrm{E} ; 54$ hectares). The circumference of all to-be cut deciduous and coniferous trees within a $20-\mathrm{m}$ radius of each nest-box was measured at breast height (small: 30-100 cm, medium: 100-200 cm, large: $>200 \mathrm{~cm}$; categories are based on the frequency distribution of logged trees in the area; see Fig. S1) 2 weeks before logging (November-December 2013; 3-4 months before the breeding season). A radius of $20 \mathrm{~m}$ was chosen, given the heavy workload of measuring individual trees, as a compromise between efficiency and biological plausibility (since birds are more likely to forage close to their nestbox) (Amininasab et al. 2016). The percentage of nestboxes around which at least one tree was logged was calculated for four randomly chosen subareas of equal size and containing a similar number of nest-boxes, in order to test for spatial differences in logging activity. Each year, from April through June, nest-boxes were checked daily to record the date of egg-laying onset (with April 1 representing day 1) and the total number of eggs laid.

\section{Statistical analyses}

For each nest-box, we calculated the pre-logging (average over 2001-2013) and post-logging (2014) laying date and total clutch size, and the change in these parameters was obtained by subtracting post-logging from pre-logging values. Because breeding parameters may differ between years (e.g., initiation of breeding in 2013 was extremely late), we calculated standardized values using the following equation:standardized $x=\frac{x-\bar{x}_{\text {year }}}{\operatorname{sd} x_{\text {year }}}$ where $x$ is the laying date or number of eggs laid, and $\bar{x}_{\text {year }}$ is the average laying date or number of eggs laid in all nest-boxes in a given year.

Considering those territories where logging occurred in at least one category, linear models were used to test for the effect of logging (whether one or more trees were cut in each category [deciduous and coniferous trees of small, medium, and large sizes]) on the change in laying date or number of eggs laid before (average over 2001-2013) and after logging (2014) in these territories (as response variable in different models). From all possible models (including the null model), we identified the best fitting model (lowest corrected Akaike information criterion [AICc] score) and all other models where $\triangle \mathrm{AICc}<2$ (Burnham and Anderson 2002; Tables S1, S2), and we averaged the parameter estimates based on the weight of these best models (Grueber et al. 2011); see Tables S3, S4) using the package 'MuMIn' in R version 3.1.1 (R Development Core Team 2015). $P$ values $<0.05$ were considered significant.

\section{Results}

Coniferous and deciduous trees were removed in 25.7 and $27.5 \%$ of 109 territories, respectively, that were occupied in the subsequent spring. There was no strong spatial effect of logging, indicated by approximately equal logging activity among four randomly assigned plots $\left(F_{3,105}=3.87, P=0.052\right)$. A total of 18 small (mean per territory $=1.55$, range $1-3), 22$ medium $($ mean $=3.27$, range $1-11)$ and 9 large (mean $=1.44$, range $1-3$ ) coniferous trees, and 19 small (mean $=3.26$, range $1-17$ ), 20

Table 1 Results of a linear model testing the relationships between change in standardized laying date of Blue Tits and logging of deciduous and coniferous trees of different sizes

\begin{tabular}{lrlll}
\hline & \multicolumn{4}{l}{ Change in laying date } \\
\cline { 2 - 5 } & Estimate & SE & $z$-value & $P$ value \\
\hline (Intercept) & 0.107 & 0.109 & 0.98 & 0.33 \\
Medium deciduous & -0.488 & 0.252 & 1.91 & 0.06 \\
Small coniferous & 0.323 & 0.253 & 1.26 & 0.21 \\
Large deciduous & -0.362 & 0.380 & 0.94 & 0.34 \\
Small deciduous & 0.218 & 0.303 & 0.71 & 0.48 \\
Medium coniferous & 0.148 & 0.237 & 0.62 & 0.54 \\
\hline
\end{tabular}

The estimated coefficients (with associated standard errors, $z$ and $P$ values) are based on averaging the models that gave the best fit (based on $\mathrm{AICc}$ )

The order of variables is based on ranking by relative importance (sum of Akaike weights). The large coniferous variable is not present in the final model, because it was not in the top model set 


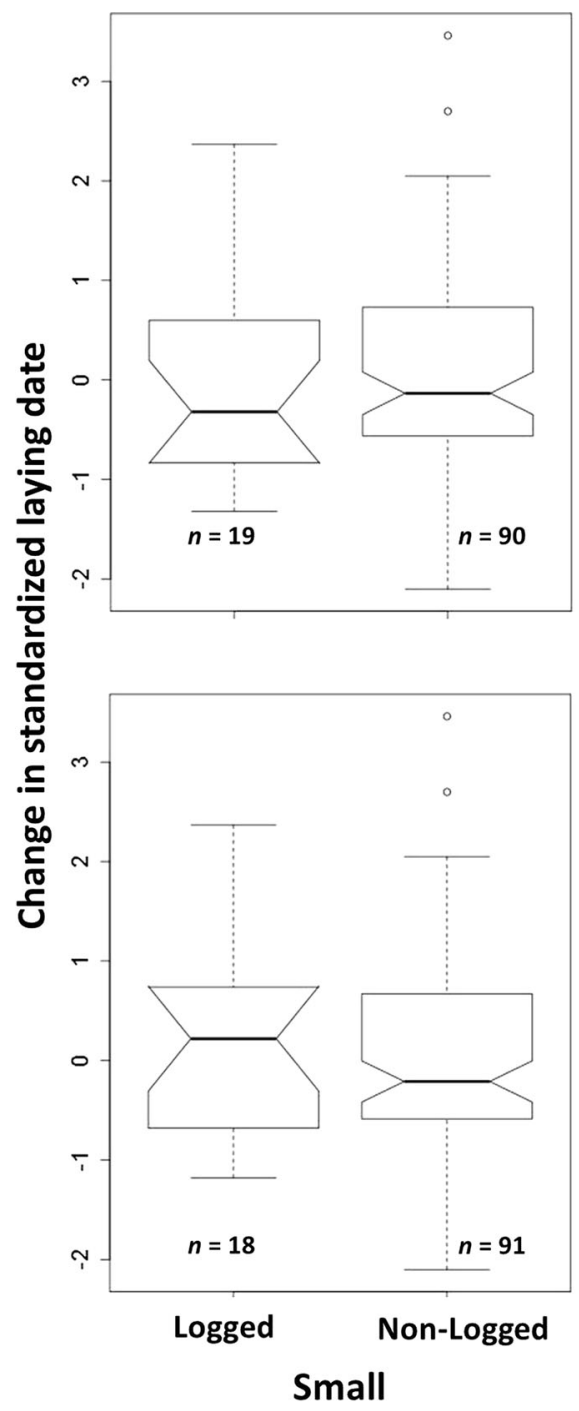

Fig. 1 Notched box-plots showing the influence of logging deciduous and coniferous trees of different sizes on change in standardized laying date of Blue Tits. Notches represent confidence intervals

medium $\quad($ mean $=2.40$, range $1-8)$ and 7 large (mean $=1.14$, range 1-2) deciduous trees were logged.

No change in laying date was found for Blue Tits with deciduous or coniferous trees of any size logged near their nest-boxes (Table 1; Fig. 1). Logging of deciduous or coniferous trees also did not affect the number of eggs laid (Table 2), with the exception of marginally significantly smaller clutches in territories where small coniferous trees were logged $(P=0.046$; Table 2; Fig. 2).

\section{Discussion}

Our results suggest that modest logging of trees has a limited effect on Blue Tit reproductive performance. Based on longitudinal analyses, we show that logging of
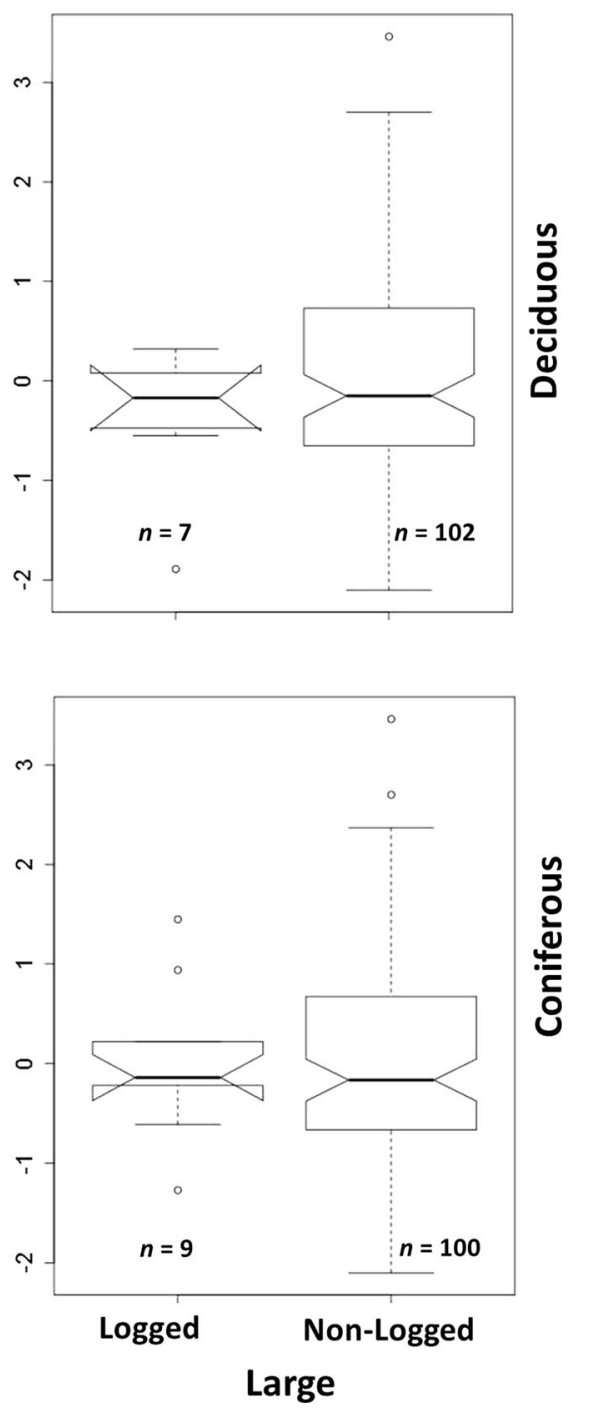

around the median, which is based on the median \pm 1.57 interquartile range $/ \sqrt{ } n$. Notches overlap in all plots, indicating that there is no strong evidence (95\% confidence) that the medians differ

coniferous or deciduous trees had no effect on laying date, and we found indication of only a small negative effect of logging of coniferous trees on the number of eggs laid. Although we could not incorporate other parameters of breeding performance (like fledging success), due to other experiments in this population (see Amininasab et al. 2016), laying date and clutch size are considered good predictors of reproductive performance, because they usually correlate with other traits like number of fledglings (Lambrechts et al. 2004) and recruitment (Boyce and Perrins 1987).

Previous studies on Blue Tits show that reproductive performance is influenced by food availability (Svensson and Nilsson 1995). Deciduous trees support more caterpillars and insects as food sources during the brood-rearing phase than coniferous or evergreen trees, possibly due to 
Table 2 Results of a linear model testing the relationships between change in standardized number of eggs laid by Blue Tits and logging of deciduous and coniferous trees of different sizes

\begin{tabular}{lcccc}
\hline & \multicolumn{2}{l}{ Change in number of eggs laid } & z-value & $P$-value \\
\cline { 2 - 5 } & Estimate & SE & 0.06 & 0.95 \\
\hline Intercept) & -0.006 & 0.103 & 1.99 & 0.046 \\
Small coniferous & -0.534 & 0.265 & 1.38 & 0.17 \\
Large deciduous & 0.539 & 0.384 & 1.09 & 0.27 \\
Medium coniferous & 0.294 & 0.267 & 0.97 & 0.33 \\
Large coniferous & 0.315 & 0.320 & 0.56 & 0.57 \\
Medium deciduous & 0.134 & 0.235 & 0.41 & 0.68 \\
Small deciduous & 0.101 & 0.246 & & \\
\hline
\end{tabular}

The estimated coefficients (with associated standard errors, $z$ and $P$-values) are based on averaging the models that gave the best fit (based on $\mathrm{AICc})$

The order of variables is based on ranking by relative importance (sum of Akaike weights)

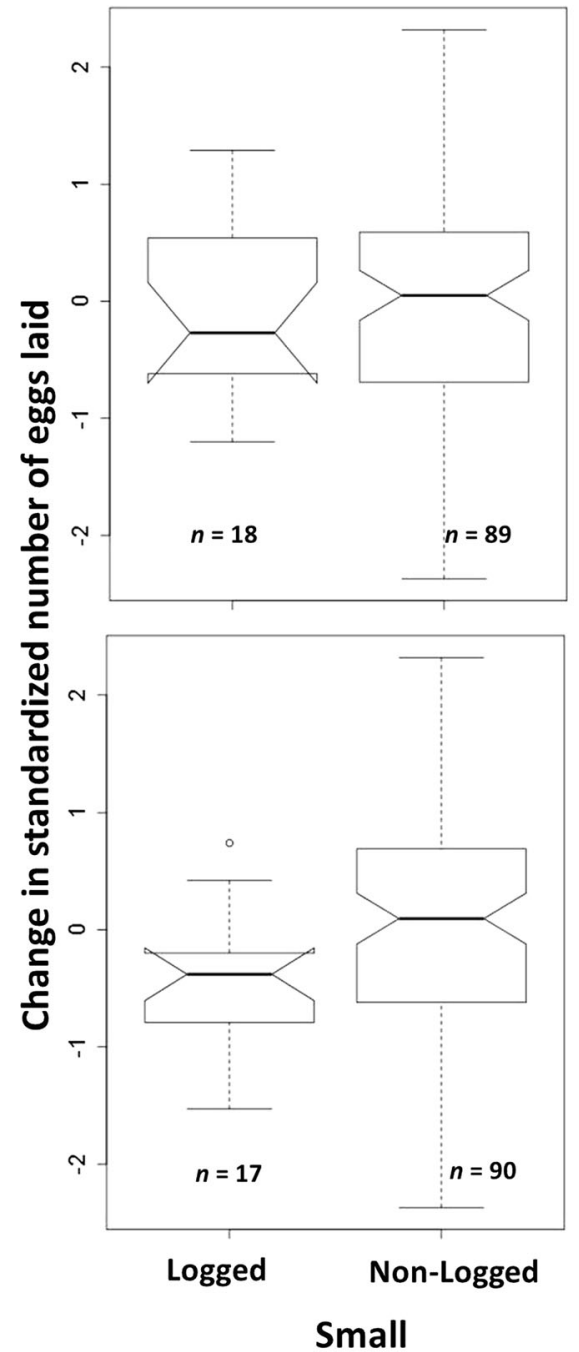

Fig. 2 Notched box-plots showing the influence of logging of deciduous and coniferous trees of different sizes on change in standardized number of eggs laid by Blue Tits. Notches represent confidence intervals around the median, which is normally based on
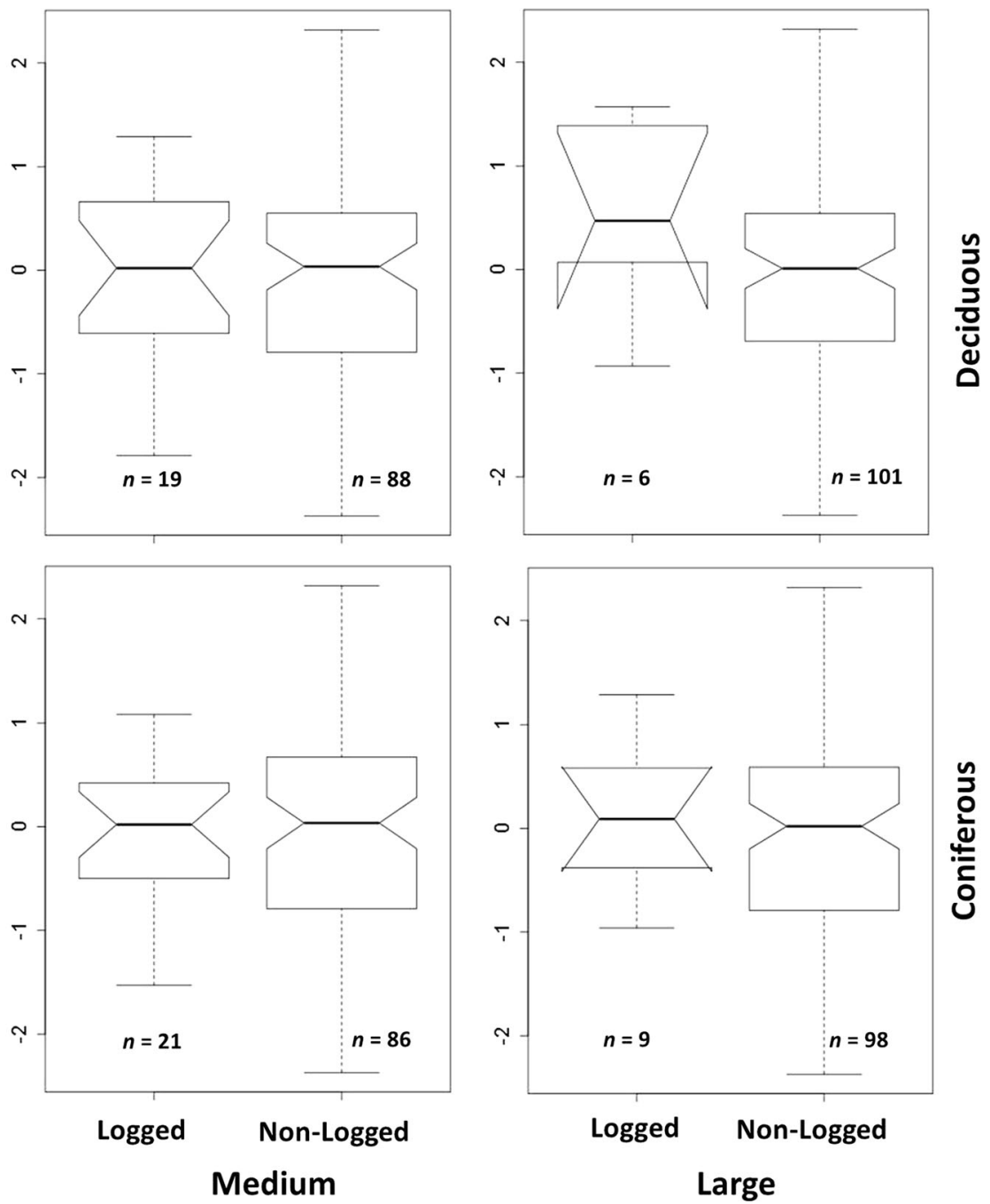

the median $\pm 1.57 \times$ interquartile range $/ \sqrt{ } n$. Notches do not overlap when testing logging of small coniferous trees, indicating that the medians differ (95\% confidence) 
differences in leaf shape, branch surface, and sap production (Perrins 1979; Lambrechts et al. 2004). Therefore, we expected to find a larger effect of logging deciduous versus coniferous trees on reproductive performance of Blue Tits, but our results did not provide any evidence that modest logging of deciduous trees had an effect. Similarly, logging of large trees was suspected to have the greatest impact on reproductive performance, because larger canopies provide more food resources for Blue Tits, but we found no effects of logging large trees.

The only significant effect we found was that of logging of small coniferous trees on the number of eggs laid. Although the effect was small, and this explanation does not explain why logging of larger coniferous trees did not affect clutch size, the relative importance of evergreen trees may increase because Blue Tit populations may adapt to foraging in coniferous habitats, depending on the environmental context (Tremblay et al. 2003; Mägi et al. 2009). Alternatively, evergreen trees may provide other benefits like yearround refuge against predators (Lambrechts et al. 2004). Removing these evergreens near nest-boxes may therefore have resulted in increased 'stress-related' hormones, leading to reduced clutch sizes (Julliard et al. 1997). Furthermore, at the onset of egg laying, males may sing more during the dawn chorus in evergreen trees, which may indirectly have a positive effect on clutch size. The fact that only logging of young coniferous trees had a relatively small effect on clutch size may be due to the greater toughness and higher levels of secondary components like tannins in the needles of mature coniferous trees, rendering them unappetizing to caterpillars and other insects (Hatcher 1990). Hence, young coniferous trees may provide better food resources for Blue Tits compared to mature trees. We can only speculate why logging of larger deciduous trees had no effect on reproductive performance, especially since a previous correlational study in this population showed that egg laying started earlier and clutch sizes were larger in habitats with more mature deciduous trees (Amininasab et al. 2016). It is possible that the small number of deciduous trees cut per territory did not significantly affect food supply, and most territories still had sufficient food resources available despite logging. Alternatively, given that vertical flight is more costly than horizontal flight, it could be that higher trees cause foraging to be more energetically costly, balancing the benefits of greater food supply.

Regardless of the mechanism, however, we show that small changes in coniferous, rather than deciduous, habitats can have effects on the reproductive performance of Blue Tits. This counter-intuitive result highlights the need for further studies to elucidate the specific ecological mechanisms (e.g., food availability, trees providing refuge, differential energetic costs of foraging) behind our results. Similarly, disturbance from noise and machinery during the logging event itself could have been an important confounding factor. However, logging occurred 3-4 months before the breeding season, which suggests that disturbance because of logging is unlikely to explain our results.

In conclusion, while we did observe borderline effects of logging small coniferous trees on Blue Tit clutch size, overall, our results suggest that modest logging did not have substantial detrimental effects on Blue Tit reproductive performance.

Acknowledgments We thank Kraus-Groeneveld Stichting for permission to work in De Vosbergen. We also thank our team of colleagues and students for assistance with field work, Peter Korsten and Han Olff for general advice, Frank Groenewoud and Kat Bebbington for statistical advice, two anonymous referees for useful comments, and Martje Birker for the summary in German. This study complies with the current laws of the Netherlands. Permission was granted by the Animal Experiments Committee of the University of Groningen. Research was supported by the Netherlands Organisation for Scientific Research (NWO-ALW 821.01.008) and other grants to J.K.

Open Access This article is distributed under the terms of the Creative Commons Attribution 4.0 International License (http://crea tivecommons.org/licenses/by/4.0/), which permits unrestricted use, distribution, and reproduction in any medium, provided you give appropriate credit to the original author(s) and the source, provide a link to the Creative Commons license, and indicate if changes were made.

\section{References}

Amininasab SM, Vedder O, Schut E, de Jong B, Magrath MJL, Korsten P, Komdeur J (2016) Influence of fine-scale habitat structure on nest-site occupancy, laying date and clutch size in blue tits Cyanistes caeruleus. Acta Oecol 70:37-44

Bourque J, Villard MA (2001) Effects of selection cutting and landscape-scale harvesting on the reproducctive succes of two neotropical migrant birds. Conserv Biol 15:184-195

Boyce MS, Perrins CM (1987) Optimizing great tit clutch size in a fluctuating environment. Ecology 68:142-153

Burivalova Z, Lee TM, Giam X, Sekercioglu CH, Wilcove DS, Koh LP (2015) Avian responses to selective logging shaped by species traits and logging practices. Proc R Soc Lond B 282:20150164

Burnham KP, Anderson DR (2002) Model selection and multimodel inference: A practical information-theoretic approach, 2nd edn. Springer, Berlin

Gram WK, Porneluzi PA, Clawson RL, Faaborg J, Richter SC (2003) Effects of experimental forest management on density and nesting success of bird species in Missouri Ozark forests. Conserv Biol 17:1324-1337

Grueber CE, Nakagawa S, Laws RJ, Jamieson IG (2011) Multimodel inference in ecology and evolution: challenges and solutions. J Evol Biol 24:699-711

Hatcher PE (1990) Seasonal and age-related variation in the needle quality of five conifer species. Oecologia 85:200-212

Julliard R, McCleery RH, Clobert J, Perrins CM (1997) Phenotypic adjustment of clutch size due to nest predation in the great tit. Ecology 78:394-404

Lambrechts MM, Caro S, Charmantier A, Gross N, Galan M, Perret P, Cartan-Son M, Dias PC, Blondel J, Thomas DW (2004) Habitat quality as a predictor of spatial variation in blue tit reproductive 
performance: a multi-plot analysis in a heterogeneous landscape. Oecologia 141:555-561

Mägi M, Mänd R, Tamm H, Sisask E, Kilgas P, Tilgar V (2009) Low reproductive success of great tits in the preferred habitat: a role of food availability. Ecoscience 16:145-157

Perrins CM (1979) British Tits. Collins, London

R Development Core Team (2015) R: a language and environment for statistical computing. R Foundation for Statistical Computing, Vienna
Svensson E, Nilsson J (1995) Food supply, territory quality, and reproductive timing in the blue tit Parus caeruleus. Ecology 76:1804-1812

Tremblay I, Thomas DW, Lambrechts MM, Blondel J, Perret P (2003) Variation in blue tit breeding performance across gradients in habitat richness. Ecology 84:3033-3043 